\title{
Dining with great chemists
}

\author{
https://doi.org/10.51167/ice00006
}

\author{
Abraham Nudelman \\ Department of Chemistry, Bar-Ilan University, Ramat Gan 5290002, Israel \\ Email: nudelman@biu.ac.il
}

This is a story with several contributing segments all of which merge at the end.

In the course of my $\mathrm{PhD}$ studies under the direction of Nobel Prize Laureate Prof. Donald Cram, I was involved in studies dealing with optically active sulfur compounds.

Upon graduation, I went for an interview with the pharmaceutical company Wyeth Laboratories in PA. After they had shown me the place they brought me to Dr. Herchel Smith the head of research. Dr. Smith asked me if was interested in joining Wyeth to which I asked on what basis was he offering me a job since I had not been requested to give a seminar and no one had asked me any relevant questions during my tour of the company. Dr. Smith replied that he had received a good recommendation for me from Prof. Cram and that was sufficient for him. I did join Wyeth.

Since I did not eat in the cafeteria, I spent my lunchtime in the library where I accumulated enough data, dealing with optically active sulfur compounds, to write a review in this field. I then contacted Dr. Norman Kharash, the editor of the journal International Journal of Sulfur Chemistry and asked him whether he would publish the review, to which he replied positively. Subsequently, I submitted a second review on this field, which was also published by Kharash. Eventually after publishing four reviews, I contacted Kharash with the fifth one suggesting we should unite all five reviews as individual chapters in a book, which was published as the Chemistry of Optically Active Compounds.
My immediate supervisor at Wyeth was a former student of Prof. E. J. Corey at Harvard. In 1972, I attended an American Chemical Society meeting where Prof. Corey was the keynote speaker lecturing on "Logic and heuristics applied to synthetic analysis," since he had invented the first computerized program for retrosynthesis. This was probably the earliest version of programs developed by SciFinder. While listening to Corey's lecture, I noticed that a senior gentleman a couple of rows behind me was happily having a good nap. At the end of the lecture I went up to the podium to give Prof. Corey regards from my supervisor. While speaking to Corey the sleepy gentleman came up and effusively congratulated Corey on the wonderful lecture presented. He then turned to me and exclaimed "Abraham, how are you," this was none other than Norman Kharash, who then asked me what my plans were and I answered that I was planning to go to see my former colleagues at UCLA. Kharash then insisted that I had to join him for lunch. As we were exiting the lecture hall, a gentleman approached us, and Kharash greeted him enthusiastically saying "Prof. Birch how are you? Where are you going." Prof. Arthur Birch replied that he was going to grab a bite, to which Kharash insisted that he join us for lunch. Now I was accompanied by two renowned chemists, whereas I was a relatively recent $\mathrm{PhD}$ graduate.

We went to a restaurant on Sunset Strip, and when the waiter showed us the menu I realized there was nothing kosher to eat, so I asked him whether it would be possible to have a green salad. The waiter told me that they did not have such, to which Karsh interceded and requested to see the chef. So,

Abraham Nudelman was born in Mexico, and received his BSc from Bar-llan University, MSc from Brooklyn College and PhD from UCLA under the direction of Nobel Laureate Professor Donald Cram. After several years in the pharmaceutical industry, he returned to Israel. After six years at the Weizmann Institute, he established the Division of Medicinal Chemistry in Bar-llan's Chemistry department. He became a Professor Emeritus in 2008 and still maintains an active lab. He was appointed an Honorable Member of the ICS in 2019.

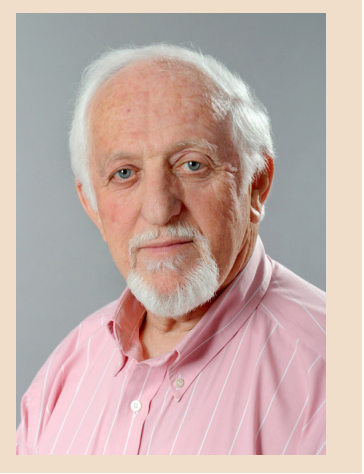


the chef with his high, white cylinder appeared by our table and Kharash asked him whether he could prepare a salad for me. The answer was positive and a short while later, the chef himself brought the most exquisite and elaborate salad I have ever seen. Everyone around was looking to see who was deserving of such a delight.

Another part of the story relates to the fact the Herchel Smith had been Arthur Birch's student, and in the course of his studies, using the famous Birch reduction reaction as a key step, developed a total synthesis for a steroid. In those days if a student invented something at Cambridge University, he could take the invention with him and patent it without needing to inform the university. Herchel Smith took his patent and sold it to Wyeth Laboratories, that developed the steroid into Ovral - Levonorgestrel. This drug became the most popular oral contraceptive in the world. In addition to the substantial sums that Dr. Smith received from Wyeth as royalties for his invention, he was also nominated as head of research, and that is how I became a medicinal chemist at Wyeth. By the way, from the royalties received from Wyeth, Dr. Smith donated over US $\$ 200$ million to Cambridge and US $\$ 100$ million to Harvard.

Now, while we were sitting at the table Kharash, Birch and me eating my salad, the conversation shifted to my place of employment. However, when I mentioned to Arthur Birch that Herchel Smith was the person who hired me, he turned all red and upset. This was due to the fact that Herchel, who had used the Birch reduction in the steroid synthesis, had not bothered to put Birch's name on the patent as a co-inventor, even though he had been involved in steroid synthesis, and therefore Birch did not get any of the royalties. You can imagine that I quickly shifted the course of the conversation.

It would be a disservice not to mention that Prof. Cram had a custom of inviting all his students every year for a barbeque dinner in his estate, which was a most enjoyable event, although all I could eat were some peanuts and raisins. One year after Prof. Cram announced the dinner date and invited us all, I went up to him and indicated that regretfully I would not be able to join that year because the date of the dinner fell on Shavuot. Without hesitation, Prof. Cram told me that the tradition of his dinners went back 20 years, whereas my Shavuot tradition went back thousands of years and, therefore, I won. He proceeded then to contact all the students and postpone the dinner to another date so that I would be able to attend and have my portion of peanuts and raisins.

This short story is a reminder of how fortunate I was to be in close contact with powerful, excellent chemists such as Herchel Smith, Donald Cram, E. J. Corey, and Arthur Birch. By the way, shortly thereafter, Herchel Smith quit Wyeth and became a granting consultant for the USA government at a salary of $\$ 1 /$ year. 